\title{
Auditory Language Comprehension in Children with Developmental Dyslexia: Evidence from Event-related Brain Potentials
}

\author{
B. Sabisch ${ }^{1,2}$, A. Hahne ${ }^{1}$, E. Glass ${ }^{2}$, W. von Suchodoletz ${ }^{2}$, \\ and A. D. Friederici ${ }^{1}$
}

\begin{abstract}
In the present study, event-related brain potentials (ERPs) were used to compare auditory sentence comprehension in 16 children with developmental dyslexia (age 9-12 years) and unimpaired controls matched on age, sex, and nonverbal intelligence. Passive sentences were presented, which were either correct or contained a syntactic violation (phrase structure) or a semantic violation (selectional restriction). In an overall sentence correctness judgment task, both control and dyslexic children performed well. In the ERPs, control children and dyslexic children demonstrated a similar N400 component for the semantic violation. For the syntactic violation, control children demonstrated a combined pattern, consisting of an early starting bilaterally distributed anterior negativity and a late centro-parietal positivity (P600). Dyslexic children showed a different pattern that is characterized by a delayed left lateralized anterior negativity, followed by a P600. These data indicate that dyslexic children do not differ from unimpaired controls with respect to semantic integration processes (N400)
\end{abstract}

\section{INTRODUCTION}

The majority of children learns to master reading and writing with a sufficient level of proficiency, but a substantial portion (4-9\%) of them has severe problems (Shaywitz, Shaywitz, Fletcher, \& Escobar, 1990). Developmental dyslexia is a developmental disorder and refers to a failure in the acquisition of reading and/or spelling skills despite adequate intelligence, education, and social background. An additional criterion that is used for defining developmental dyslexia is a significant difference between nonverbal intelligence and spelling and/or reading skills (Dilling, Mombour, \& Schmidt, 1993). In a number of cases reading skills improve with age (Georgiewa et al., 2004; Pennington, Van Orden, Smith, Green, \& Haith, 1990), whereas spelling prob-

\footnotetext{
${ }^{1}$ Max Planck Institute for Human Cognitive and Brain Sciences, Leipzig, Germany, ${ }^{2}$ Ludwig-Maximilians-University, Munich, Germany
}

or controlled processes of syntactic reanalyses (P600) during auditory sentence comprehension. However, early and presumably highly automatic processes of phrase structure building reflected in the anterior negativity are delayed in dyslexic children. Moreover, the differences in hemispheric distribution of the syntactic negativity indicate different underlying processes in dyslexic children and controls. The bilateral distribution in controls suggests an involvement of right hemispherically established prosodic processes in addition to the left hemispherically localized syntactic processes, supporting the view that prosodic information may be used to facilitate syntactic processing during normal comprehension. The left hemispheric distribution observed for dyslexic children, in contrast, suggests that these children do not rely on information about the prosodic contour during auditory sentence comprehension as much as controls do. This finding points toward a phonological impairment in dyslexic children that might hamper the development of syntactic processes. lems have a lifelong persistence. As a consequence, dyslexia leads very often to problems in school and subsequently to limited opportunities in realizing occupational objectives (Esser, Wyschkon, \& Schmidt, 2002). Developmental dyslexia is one of the most frequently diagnosed developmental disorders in childhood, and recent evidence suggests that it has a genetic origin. This genetic approach of dyslexia is mainly supported by twin studies (Davis et al., 2001) and linkage studies (for an overview, see Fisher \& DeFries, 2002; Fisher et al., 2002).

During the last decade, research on developmental dyslexia has accumulated, and yet the theories about mechanisms underlying this deficit are still controversial (Ramus et al., 2003; Witruk, Friederici, \& Lachmann, 2002; Habib, 2000; von Suchodoletz, 1999). We will start by briefly reviewing two of the most prominent theories in current research on developmental dyslexia, the phonological deficit hypothesis and the auditory deficit hypothesis. 
According to the phonological deficit hypothesis (e.g., Goswami, 2003) dyslexia results from a specific impairment of the phonological representations and related processes one has to perform to read and to write. Learning to read requires the understanding that a single word can be segmented into small units of sound, which ultimately correspond to single graphemes. This process, called phonological awareness, is divided into three different linguistic levels, syllables, onset rhymes, and phonemes. The awareness of syllables and onset rhymes develops before literacy acquisition, whereas awareness of single phonemes emerges as reading and writing are taught (Goswami, 2003). Even for children with developmental dyslexia, the awareness of syllables and onset rhymes improves very rapidly during the earliest phase of literacy acquisition (Landerl, Wimmer, \& Frith, 1997). However, their awareness of phonemes is still impaired even after reading and writing have been taught, and this impairment seems to persist into adulthood (Snowling, Nation, Moxham, Gallagher, \& Frith, 1997).

The auditory temporal processing deficit hypothesis, proposed by Tallal, Miller, and Fitch (1993) and Tallal and Piercy (1973, 1974), goes one step further and claims that a deficit in the processing of transient (within milliseconds) or rapidly changing acoustic tones leads to difficulties in the perception of phonemes. In this view, developmental dyslexia is caused by a primary deficit in the auditory temporal analysis, which yields as a consequence a phonological deficit and subsequently leads to difficulties in the acquisition of reading and spelling (Tallal \& Stark, 1982; Tallal, 1980).

Despite the difference in the origin of the deficit underlying developmental dyslexia, both theories assume that the development of phonological representations is deficient in children with developmental dyslexia. Up to now, most studies on developmental dyslexia focused on single phonemes or syllables, that is, segmental information (Ramus, 2001). Phonological representations, however, encode different levels of segmental information (e.g., individual phonemes), but also suprasegmental information such as word stress, intonation, and rhythm. Based on this observation, we ask the question whether, in addition to the deficiency in processing phonological representations and processes concerning segmental information, the processing of suprasegmental information is deficient in children with developmental dyslexia.

Studies with young unimpaired language learners (Jusczyk, 2002) and children with developmental language impairment (Weinert, 1992) suggest that suprasegmental phonological information, in particular prosodic information provide an important cue in discovering the syntactic structure of a language. The assumption is that the speaker's task during understanding a sentence is to segment the speech input into major syntactic constituents such as phrases and clauses. In general, boundaries are reliably marked by prosodic cues (e.g., preboundary lengthening, falling pitch at the end of the clause; Snow \& Balog, 2002). According to previous research, infants are sensitive to such cues and prefer pauses at syntactic boundaries compared with pauses within syntactic constituents (Hirsh-Pasek et al., 1987).

Breaking down the speech stream into phrases or clauses might further help to discover the underlying syntactic structure within prosodic phrases. For example, function words (e.g., determiner, the) are likely to occur at certain edges (i.e., boundaries) with respect to the prosodic phrase. Because the function word the signals the beginning of a noun phrase, once the location of such a phrase is detected, it also helps to find the location of other elements within the same syntactic constituent (Jusczyk, 2002). Further evidence for the connection between syntax and prosody comes, for instance, from a study with 7- to 9-month-old German infants who recognized the internal structure of a noun phrase (the + content word) in continuous speech (Höhle \& Weissenborn, 2003). As for the importance of prosody in acquiring syntactic rules, Weinert (1992) showed that normal control children were able to learn the syntactic rules from prosodically enriched sentences, whereas children with developmental language impairment could not make use of the available prosodic information for the acquisition of syntactic rules.

Following from these observations, we hypothesize that children with developmental dyslexia might also be deficient in processing syntactic information. This hypothesis is guided by the following suggestions from previous research: (1) children with developmental dyslexia are impaired in the processing of suprasegmental information (Ramus, 2001); (2) prosodic information provide an important cue in the acquisition of syntactic rules for normal children; and (3) children with developmental dyslexia are deficient in the processing of gender and number agreement, which represent information encoded in the syntactic domain (Jiménez et al., 2004). In other words, our proposal is that if children with developmental dyslexia are deficient in processing prosodic information, they might as well be deficient in processing syntactic information, because prosodic and syntactic information are closely connected as described above.

The critical question then is, "Are dyslexic children with problems in reading and writing impaired in syntactic processing as well as phonological processing or either syntactic or phonological processing alone?" This is an important question that we address in the research reported here, as our hypothesis about dyslexia ties syntactic processes with prosodic processes, and it is therefore essential to determine the exact nature of the relation between these two processes. In addition, independent from our hypothesis, there has been a long-lasting debate whether children with developmen- 
tal dyslexia have an impairment in syntactic processing at all. It has been proposed that better developed syntactic abilities can facilitate the development of reading and writing (for the study on normally developing children, see the work of Muter \& Snowling, 1997; for the study on dyslexia, see the work of Nation \& Snowling, 2000). Moreover, it was reported that normally developing children showed a higher reading proficiency when they could use syntactic and semantic information (e.g., for syntax, word order rules; for semantic, word knowledge) as context information to predict the upcoming word (Rego \& Bryant, 1993).

The present study was conducted to investigate whether our assumption holds that children with developmental dyslexia differ from control children in syntactic processing, and if so, whether this is because of differences in prosodic processes that have an impact on the syntactic processing. In addition, we investigated the use of syntactic and semantic contextual information during sentence comprehension. We utilized eventrelated brain potentials (ERPs), which for many years have been proven to be a very useful time-sensitive on-line measurement for language processing. In addition, this method has been used successfully to investigate the developmental changes in normally developing children in sentence comprehension processes (Hahne, Eckstein, \& Friederici, 2004) as well as the on-line use of prosodic information in sentence comprehension (Steinhauer, Alter, \& Friederici, 1999).

Before moving on to the next section, we will briefly summarize the major findings in the previous ERP research regarding adult sentence comprehension, because these will guide us in the interpretation of the data on children reported in the present article. In relation to the processing of syntactic, prosodic, and lexical-semantic information, different ERP components have been reported by using violation paradigms (for an overview, see Friederici, 2002) that contrast correct sentences with sentences containing a specific linguistic violation. In relation to the processing of lexical-semantic information, an ERP component called N400 (centroparietal negativity occurring between 300 and 500 msec poststimulus onset) was found (for an overview, see the work of Kutas \& Federmeier, 2000). The N400 is elicited by semantic anomalies such as selectional restriction violations, in which a word cannot be integrated in the preceding context. It is assumed that the N400 reflects processes of lexical-semantic integration. With respect to syntactic information, two ERP components, the so-called ELAN (early left anterior negativity registered between 100 and $300 \mathrm{msec}$ ) and the P600 (late parietal positivity elicited between 500 and $1000 \mathrm{msec}$ ) were reported. Syntactic violations, realized by phrase structure violations, elicit an ELAN that is thought to reflect early processes of phrase structure building (Hahne \& Friederici, 1999). The P600 is commonly assumed to represent syntactic processes of reanalysis and repair (for an overview, see the work of Hagoort, Brown, \& Osterhout, 1999). In a recent study, Eckstein and Friederici (2005) reported a right anterior negativity (RAN) for prosodic incongruities, resulting from the mismatch between the syntactic structure and the prosody expected for that particular syntactic structure in a sentence. In a further study, Eckstein and Friederici (in press) showed that a prosodic incongruity could influence early syntactic phrase structure building processes (reflected in the ELAN) by additional involvement of right anterior regions.

\section{Present Study}

The major question that the present study focuses on is whether children with dyslexia are different from normally developing control children in the processing of prosodic information and, as a consequence, also in the processing of syntactic information. To control whether possible differences observed between unimpaired control children and children with developmental dyslexia are specifically related to the domains of prosody and syntax, we also tested the ERP response to lexicalsemantic anomalies. This study also investigates segmental and suprasegmental information because we want to examine whether children with developmental dyslexia are impaired in the processing of segmental phonology, as frequently reported in the literature and considered to be the origin of developmental dyslexia by the phonological deficit hypothesis. In addition, this study tries to disentangle whether children with developmental dyslexia and unimpaired control children differ in the processing of auditory information, as postulated by the auditory temporal deficit hypothesis.

In the ERP experiment, we used a well-established paradigm in which correct conditions and two violation conditions, namely a syntactic and for control purposes, a semantic violation condition were presented. The syntactic violation condition contained two different aspects, a phrase structure violation (syntactic level) and a prosodic incongruence (prosodic level). In more detail, our test sentences contained a noun phrase followed by an auxiliary, a prepositional phrase, and the past participle. On the syntactic level, the prepositional phrase requires a noun phrase (e.g., noun or adjective plus noun) immediately after the preposition. In our test sentences for the syntactic violation condition, however, the noun phrase was spliced out, and a past participle immediately appeared after the preposition, yielding an ungrammatical construction. On the prosodic level, a preposition signals that additional constituents should follow. Specifically, the word immediately following the preposition was not expected to convey the sentence or phrase final prosody. Because the noun phrase was removed by the splicing procedure, the constituent following the preposition contains sentence final pros- 
ody and therefore resulted in an incongruent continuation of the sentence melody. For the semantic violation condition, the selectional restriction of the verb did not match with the noun phrase at the subject position (e.g., in "The volcano was eaten," the noun phrase "the volcano" does not satisfy the selectional restriction of the verb eaten and cannot be integrated).

The predictions are as follows. For the syntactic violation condition, we hypothesize that unimpaired control children show a left anterior negativity (representing early processes of phrase structure building) and a RAN (representing the detection of the prosodic incongruent sentence continuation). Using the identical violations in sentences with passive constructions, an early left anterior adultlike negativity was found for 13-year-olds but not for younger children who demonstrated a sustained bilaterally distributed anterior negativity (Hahne et al., 2004). The more bilateral distribution of the negativity was attributed to a possible involvement of the right hemispherically localized prosodic processes (Friederici \& Alter, 2004) that may support syntactic processes during development. Based on the assumption that children with developmental dyslexia might differ in processing prosodic information, we hypothesize that this should result in a modulation in latency or amplitude of the anterior negativity over the right electrode sites. Assuming that prosody supports the acquisition of syntactic rules, early processes of phrase structure building should be particularly affected in dyslexic children, and this in turn should also be reflected in latency or amplitude modulations for the ELAN. For the syntactic violation condition, we predict a P600 component in addition to the anterior negativity for the control children. From developmental studies, we know that the P600 is present in young children (for active sentences, Oberecker, Friedrich, \& Friederici, 2005) and in normally developing children from 7 years on (for sentences of passive voice, Hahne et al., 2004). Because the processes of reanalyses and repair, reflected in the P600, are established early during development, we expect children with developmental dyslexia to show a similar P600 component as the control children.

In the semantic violation condition, the past participle cannot be integrated into the preceding context, and in line with previous findings, an N400 component is expected (cf. Kutas \& Federmeier, 2000). Two studies that used the identical or similar semantic violation condition reported an N400 component for normally developing children from the age of 5 years onward (Hahne et al., 2004; Holcomb, Coffey, \& Neville, 1992). Neville, Coffey, Holcomb, and Tallal (1993) found for a group of children with language impairment an increased amplitude of the N400, whereas Bonte and Blomert (2004) reported similar N400 components for children with dyslexia and control children. We expect a similar N400 component for the unimpaired control children and children with developmental dyslexia.

\section{METHODS \\ Participants}

Sixteen children with developmental dyslexia and 16 control children (ranging in age between 9 years 5 months and 12 years 10 months; mean age $=11$ years 1 month; $S D=1$ year 1 month) were tested. The children in both groups were matched pairwise on age, sex, and nonverbal IQ. The paired $t$ test revealed no significant difference between the two groups on their age and nonverbal IQ (see Table 1). The children with developmental dyslexia were selected from a sample of participants either referred to a special outpatient unit for developmental disorders at the Child and Adolescent Psychiatry of the Ludwig-Maximilians-University in Munich or from schools for children and adolescents with specific problems in literacy and language. Control children attended local schools of the urban area of Munich and were recruited via letters.

All participants, both control children and children with developmental dyslexia, were German-speaking monolinguals, and none of them had any hearing deficit

Table 1. Descriptive Data for the Control and Dyslexic Children (Mean $\pm S D$ )

\begin{tabular}{|c|c|c|c|c|}
\hline & Controls & Dyslexic Children & Differences ( $t$ Value) & p Value \\
\hline Age (years; months) & $11 ; 1 \pm 1 ; 0$ & $11 ; 1 \pm 1 ; 1$ & 0.99 & .34 \\
\hline Sex (male/female) & $9 / 7$ & $9 / 7$ & & \\
\hline Nonverbal IQ ${ }^{\mathrm{a}}$ & $104.9 \pm 8.4$ & $104.9 \pm 11.1$ & 0.00 & 1.0 \\
\hline Spelling test ${ }^{\mathrm{b}}$ & $53.7 \pm 11.1$ & $29.4 \pm 4.0$ & 7.63 & $<.001$ \\
\hline Reading test ${ }^{\mathrm{b}}$ (speed) & $52.2 \pm 6.2$ & $37.5 \pm 8.0$ & 5.61 & $<.001$ \\
\hline Reading test ${ }^{\mathrm{b}}$ (error rate) & $54.0 \pm 7.5$ & $33.5 \pm 9.3$ & 6.36 & $<.001$ \\
\hline
\end{tabular}

${ }^{\mathrm{a}} \mathrm{IQ}$ scores $(M=100, S D=15)$.

${ }^{\mathrm{b}} t$ scores $(M=50, S D=10)$. 
(confirmed by an audiometric screening procedure) or reported a history of neurological disorders (assessed by parent questionnaire and spontaneous electroencephalogram [EEG]). Furthermore, all of them had a nonverbal IQ within the normal range. The nonverbal IQ of children older than 12 years 5 month was measured by the German version of the Wechsler Intelligence Scale for Children (Wechsler, 2000) and the nonverbal IQ of younger children was assessed by the Kaufman-AssessmentBattery for Children (Kaufman \& Kaufman, 1991). In addition, we assessed all participants' reading abilities by using the Zürcher Lesetest (Linder \& Grissemann, 1980). Although this test had no updated norms, it is the only reading test in German that provides norms from grades 2 to 6 . The test was particularly appropriate for the present purpose, allowing the assessment of reading errors and reading speed.

Children with developmental dyslexia had been diagnosed based on the criteria of the International Classification of Diseases, 10th Revision (ICD-10; Dilling et al., 1993). Their spelling abilities were at least 1.5 standard deviations below the mean on a standardized score in the spelling test according to their attended school grade (Weingartener Grundwortschatz RechtschreibTest, WRT 3+, Birkel, 1994a; WRT 2+, Birkel, 1994b; Diagnostischer Rechtschreibtest, DRT 5, Grund, Haug, \& Naumann, 1995; DRT 4, Grund, Haug, \& Naumann, 1998; DRT 3, Müller, 1997; Westermann RechtschreibTest, WRT 4/5, Rathenow, 1979; WRT 6+, Rathenow, Vöge, \& Laupenmühlen, 1980). Furthermore, they had to show a discrepancy of at least one standard deviation between the nonverbal IQ score and the score in the spelling test.

The control children had to have no signs of developmental or psychiatric disorders. This was confirmed by the Child Behavior Checklist (CBCL/4-18; Achenbach, 1998) and a parent questionnaire. Control children who scored above $60 t$ scores on the main scale or any subscales of the CBCL (externalizing and/or internalizing disorders) were excluded from the study. In addition children were excluded when their parents reported any signs of a developmental disorder in the parent questionnaire (e.g., hyperactivity). All participants' parents were given informed consent. The study was approved by the Ethical Committee of the Ludwig-MaximiliansUniversity.

To assess the phonological awareness, a phoneme substitution task (Wimmer, 1993; Landerl, Linortner, \& Wimmer, 1992) was applied. Moreover, an oddity task (Berwanger, 2002), similar to the task developed by Bradeley and Bryant (1985), was used to measure rhyme awareness. The phoneme substitution task, and the oddity task had two different versions each, one for children in Grade 1 and the other for children in Grade 2.

The version for children in Grade 2 contained test items that were mono-, bi-, tri-, or quatrosyllabic words. They were presented as single words or embedded in sentences. Participants had the task to replace the vowels such as $a, e, u$, and $o$ by the vowel $i$. After a training session, the first two items had to be answered correctly, otherwise the assessment test continued with the phoneme substitution task of Grade 1 . The version for Grade 1 only contained mono- and/or bisyllabic words, having only the vowel $a$, which again had to be replaced by $i$.

In the oddity task, 10 groups of four words were presented, and the children had to identify a phonotactically odd word, which differed from the rest of the words in either its medial or final sound. From Grade 2 onward, 90\% of all items were bisyllabic words. In more detail, among the 10 groups of words provided, half of the groups contained odd words with either a voiceless or voiced sound (e.g., Grube, Stube, Hupe, Tube), and the remaining five groups contained odd words with either a labial or alveolar sound (e.g., Rappe, Kappe, Ratte, Mappe). Again, after a training session, three of the first four items had to be answered correctly, otherwise testing continued with the oddity task for Grade 1.

\section{Stimuli and Event-related Brain Potential Experiment}

The experiment consisted of 192 sentences in the passive voice that were identical to those used in previous studies with adults, children, and second-language learners (Hahne et al., 2004; Hahne \& Friederici, 2002). Altogether, four experimental conditions, two correct conditions and two incorrect conditions, each including 48 sentences were auditorily presented. One of the correct conditions contained sentences that consisted of a noun, an auxiliary, and a past participle ("Das Brot wurde gegessen." ["The bread was eaten."]). The other correct condition additionally included a prepositional phrase ("Die Pizza wurde im Restaurant gegessen." ["The pizza was eaten in-the restaurant."]). In contrast, the two incorrect conditions contained sentences that were either semantically or syntactically incorrect. In the semantic violation condition, the selectional restrictions of the verb were violated ("Der Vulkan wurde gegessen." ["The volcano was eaten."]). In the syntactic violation condition, sentences consisted of a noun, an auxiliary, and a preposition. In this condition, a noun or an adjective was expected to follow the preposition; however, a past participle was presented immediately after the preposition. This resulted in a violation of the phrase structure ("Das Eis wurde im gegessen." ["The ice cream was in-the eaten."]). In all conditions, the participles represented the target words, beginning with the morpheme ge-, which marks the regular form of German participle forms.

All sentences were spoken by a female native speaker of German and recorded on a digital audio tape. The 
taped sound files had a resolution of 16-bit and were sampled at $20 \mathrm{kHz}$. To establish a precisely time-locked presentation of all items, the auditory signal and the oscillogram were compared, and the onset of each word was marked on the time scale. Sentences of both correct conditions and the semantic violation condition were naturally spoken. Syntactically incorrect sentences were created in the following way: First, a correct sentence with a prepositional phrase was produced by the speaker (e.g., "Das Eis wurde im Gebrumm gegessen." ["The ice cream was in-the hum eaten."]). Afterward, the noun (e.g., Gebrumm [bum]) was spliced out from the recorded sentence (see Figure 1). To prevent the participants from recognizing the splicing point and to control for coarticulation of the phonemes at the critical transition between the preposition and the past participle, the following constraints were set up: (1) the noun (e.g., Gebrumm [bum]) and the past participle (e.g., gegessen [eaten]) had an identical onset phoneme; (2) the last phoneme of the preposition (e.g., im [in-the]) and the noun (e.g., Gebrumm [bum]) were identical. A behavioral experiment (Hahne \& Friederici, 2002) showed that the splicing procedure alone did not lead to unnaturalness in prosody as long as the procedure is carefully adapted in test sentences. In this experiment, participants listened to the violation conditions (without a splicing) and their counterparts created by using a splicing procedure, which either controlled coarticulation of the phonemes in the splicing position or lacked such an experimental manipulation. Participants were asked to judge whether sentences contained any splicing. The results indicated that the participants could not reliably detect splicing points when the sentences were created by controlling for coarticulation. In contrast, when coarticulation was not controlled in the spliced sentences, the participants classified these sentences as spliced.

Although the syntactically incorrect sentences were created by controlling for coarticulation at the local transition between the preposition and the past participle, they also induced a manipulation of the prosodic contour, resulting in an incongruent continuation of the sentence melody that does not satisfy the parsers expectations. Note that German is a verb-final language, which in a passive construction requires the participle to be in sentence final position. In more detail, by encountering the preposition of this passive construction, the parser expects ongoing speech, and therefore at least two more words should appear to have a congruous continuation. The first word (e.g., noun or adjective) that immediately follows the preposition cannot contain the sentence final intonation in this passive construction, whereas the second and at the same time last word (e.g., past participle) should do so. In the syntactically incorrect sentences, in which the noun of the prepositional phrase was spliced out, the parser now encounters a word that contains the sentence final prosody immediately after the preposition
Figure 1. The splicing procedure is illustrated by the oscillogram and the fundamental frequency $\left(f_{0}\right)$ for a sentence with a complete prepositional phrase (upper) and the spliced version of the identical sentence (lower). The scissors $x_{0}$ indicate the splicing points. The past participle gegessen contains the sentence final prosody that is marked by the following four prosodic features: (1) starting point of the past participle (gegessen) is higher than that of the noun (Gebrumm); (2) $f_{0}$ maximum of the past participle is higher than that of the noun; (3) sharp fall in the $f_{0}$ contour at the end of the past participle; (4) small $f_{0}$ rise at the end of the past participle following the sharp fall described in the third prosodic feature.

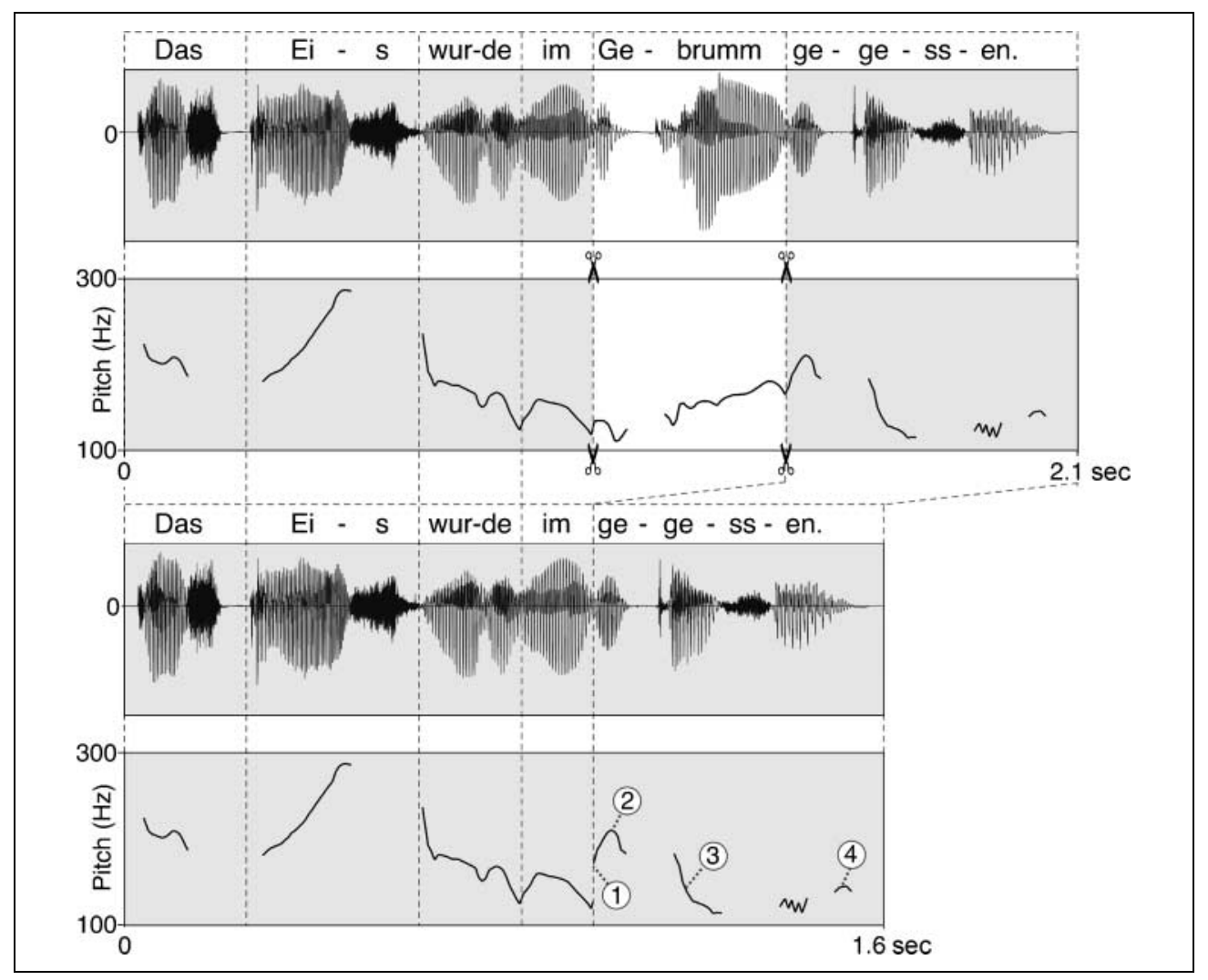


(see Figure 1, lower), which leads to an incongruent prosodic contour.

\section{Procedure}

The diagnostic procedure and the ERP recording were carried out in two sessions. Each of them took approximately 2 hours and was conducted at the research center of the Child and Adolescent Psychiatry of the Ludwig-Maximilians-University. At the end of the two sessions, participants received an age-appropriate reward for participating in the study (e.g., toys for younger children and movie tickets for teenagers). During the first session, all diagnostic data were collected. The second session included the audiometric screening, the hand preference test, the ERP experiment, and a spontaneous EEG.

Pure tone audiometry was used to measure hearing at frequencies varying from low pitch $(250 \mathrm{~Hz})$ to high pitch $(6000 \mathrm{~Hz})$. Tones were presented via headphones, either to the left or the right ear. Participants had to signal to the experimenter whenever they heard a tone by raising their hand corresponding to the ear where the tone had been detected. Participants that scored the hearing threshold level with a score of $25 \mathrm{~dB}$ or higher were excluded from the study.

In the ERP experiment, participants were seated in a comfortable chair that was placed approximately $1.5 \mathrm{~m}$ away from a computer screen. They were instructed to listen carefully to the sentences presented via loudspeakers. The experiment was divided into four blocks, each containing 48 trials, with breaks in between that lasted as long as the participants wanted. At the beginning of each block, a wizard appeared in the middle of the computer screen, which gradually became smaller and finally disappeared by $1200 \mathrm{msec}$. Each trial started with three exclamation marks that were shown for $500 \mathrm{msec}$ before the presentation of a sentence. When the sentence was played, the small wizard appeared again on the screen and remained until 3000 msec after the offset of the sentence. Participants were requested to fixate on the wizard and to avoid eye blinks and movements. After the sentence offset, there was a break of $3000 \mathrm{msec}$ to prevent any movement elicited by the button press interfering with EEG recordings. After the break, participants were instructed to judge the correctness of the sentence by pressing one of two buttons on a reaction panel, which was held with their hands during the experiment. A sticker of a smiling face and a frowning face, each corresponding to correctness and incorrectness, were attached to the buttons on the reaction panel. The smiling and frowning faces were also shown on the computer screen. They remained for $2000 \mathrm{msec}$. This was also the maximum response time that was given. The next trial started after a break of 1500 msec. The sentences were presented in pseudorandomized order whereby only three sentences of the same condi- tion could appear in succession. Furthermore, the same type of sentences (i.e., correct or incorrect sentences) did not appear more than four times in a sequence. Before the experiment started, a short introduction was given, which explained that a wizard played a magic trick and produced both correct and incorrect sentences. Afterward, 15 practice trials were applied, to ensure that the participant had understood the task before the actual experiment took place.

\section{Electroencephalogram Recording}

ERP data were recorded from $22 \mathrm{Ag} / \mathrm{AgCl}$ electrodes following the international 10-20 system (Jasper, 1958), placed in the positions FP1/2, F7/8, F3/4, Fz, FT9/10, T3/4, C3/4, Cz, T5/6, P3/4, Pz, O1/2, and Oz. Blinks and vertical eye movements were monitored by a bipolar montage, using two electrodes that were placed above and below the right eye. Similarly, by using a bipolar montage again, the horizontal eye movements were recorded from two electrodes, located at the outer left and right canthus. The EEG signals were recorded with a right mastoid reference. The activity over the left mastoid was recorded as well. All EEG recordings were rereferenced off-line to the average of the EEG signals recorded at the right and the left mastoid. The electrode placed at AFz was used as ground. All electrode impedances were kept below $5 \mathrm{k} \Omega$. The electrophysiological signals were filtered with a bandpass filter from 0.16 to $30 \mathrm{~Hz}$ and digitized at a rate of $256 \mathrm{~Hz}$.

\section{Data Analyses}

Separate analyses were conducted for the behavioral and ERP data. The performance, reflecting the percentage of correct responses per condition, was calculated separately for each participant. A selection criterion used here was calculated based on the binomial distribution. Therefore, the data with only the participants who performed above a chance level, with at least $60 \%$ of correct trials, were analyzed and are discussed in the following.

For the ERP analysis, only the trials with correct responses were analyzed. As the first step, the standard deviation of the mean amplitude within a 200-msec sliding window was calculated. Whenever the standard deviation exceeded a threshold of $40 \mu \mathrm{V}$, this part of the EEG signal was automatically marked as artifact. Afterward, the trials with artifact markings were inspected and were rejected manually if in fact those trials had real artifacts (e.g., jaw or head movements, disturbance of EEG due to technical problems). As the second step, trials with typical eye movements were marked and corrected by applying an electrooculogram correction tool (xeog, EEP software 3.1 for Unix; Nowak \& Pfeifer, Leipzig, Germany).

Table 2 provides the mean number of retained trials for each condition and each group (dyslexic and control 
Table 2. Mean Number $( \pm S D)$ of Remained Trials for the Control and the Dyslexic Children

\begin{tabular}{lcccc}
\hline & Correct & Semantically Incorrect & Syntactically Incorrect & All Conditions \\
\hline Control children $(n=16)$ & $27.9 \pm 7.4$ & $26.9 \pm 7.0$ & $27.4 \pm 8.3$ & $27.4 \pm 7.2$ \\
Dyslexic children $(n=16)$ & $22.3 \pm 3.9$ & $23.2 \pm 4.8$ & $22.7 \pm 5.2$ & $22.7 \pm 4.1$ \\
\hline
\end{tabular}

children). These mean numbers of trials were submitted to a repeated measure analysis with the variables condition (serving as the within-subject factor) and group (serving as the between-subject factor). There was no reliable main effect of condition $(F<1)$ and no significant interaction (Condition $\times$ Group interaction, $F<1$ ). The between-subject factor revealed a significant main effect, $F(1,30)=5.16, M S E=8.57, p<.05$, due to a better overall performance of the control participants. Epochs of $1500 \mathrm{msec}$, beginning from the onset of the critical past participle, were extracted from the continuous EEG data. In addition, a baseline correction with a 100-msec poststimulus onset baseline was applied (Hahne \& Friederici, 1999). Statistical evaluation of the ERPs was performed on the mean amplitude for specific time windows (TWs) relative to the onset of the past participle. The TWs were defined based on the results of previous studies concerning normally developing children (Hahne et al., 2004; Byrne et al., 1999; Holcomb \& Neville, 1991) and the visual inspection of the grand averages from the present study with the restriction that the selected TWs do not cover more than one component.

Four TWs (300-400, 400-650, 650-800, and 1000$1500 \mathrm{msec}$ ) were chosen to compare semantically incorrect with correct sentences, and three different TWs (100-300, 300-600, and 600-1300 msec) were chosen to compare the sentences containing the syntactic violation with those of the correct condition. Repeated measure analyses of variance (ANOVAs) were performed for each TW, following a hierarchical schema for the analysis. The between-subject factor group (dyslexic children vs. control children) and three within-subject factors (condition: correct vs. incorrect; hemisphere: left vs. right; region: anterior vs. posterior) were defined for analyses of 16 lateral electrodes. The variables hemisphere and region were completely crossed, yielding four regions of interest, each of which had four electrodes: left anterior (FP1, F7, F3, and FT9), right anterior (FP2, F8, F4, and FT10), left posterior ( $\mathrm{C} 3, \mathrm{~T} 5, \mathrm{P} 3$, and $\mathrm{O} 1)$, and right posterior ( 4 4, T6, P4, and O2). The analysis of the midline electrodes included the between-subject factor group (dyslexic children vs. control children) and the within-subject variables condition (correct vs. incorrect) and the four electrodes $\left(\mathrm{Fz}, \mathrm{Cz}, \mathrm{Pz}\right.$, and Oz). ${ }^{1}$ Whenever a significant interaction between the factors group and condition and one of the topographical variables was reached $(p<.10)$, a follow-up analysis for each group on the topographical level (left anterior, right anterior, left posterior, and right posterior) was performed. Greenhouse-Geisser-corrected $p$ values were reported whenever a variable with more than two levels was included in the statistical test.

To obtain further information about early auditory perception, independent from prosodic, syntactic, and lexical-semantic information, auditory evoked potentials elicited at the onset of the sentence were analyzed. For the auditory sentence onset potentials, latencies of the peak amplitude were measured for each participant, using an automatic peak detection within three distinct TWs (P1 positive peak between 30 and $100 \mathrm{msec}$, N1 negative peak between 80 and $140 \mathrm{msec}$, and P2 positive peak between 150 and $250 \mathrm{msec}$ ). Auditory sentence onset potentials were averaged over a 500-msec epoch with a 100-msec prestimulus baseline. Ponton, Eggermont, Khosla, Kwong, and Don (2002) showed that the P1N1-P2 complex is most prominent over central electrodes. Therefore, the peak latencies at $\mathrm{C} 3, \mathrm{C} 4$, and $\mathrm{Cz}$ were measured for each component. Paired $t$ tests were used to compare the peak latencies of the P1-N1-P2 complex for both groups of participants.

\section{RESULTS}

\section{Behavioral Data}

\section{Phonological Awareness}

Table 3 lists the means and standard deviations of the scores (correct answers) obtained in the phoneme substitution task and the oddity task, separately for each group. $^{2}$

The nonparametric Wilcoxon test (one-tailed) showed a significant effect for the phoneme substitution task, showing a better performance of the control children over the dyslexic children $(z=-2.94, p<.001)$. For the oddity task, again a significant difference was observed

Table 3. Means $( \pm S D)$ of Performance of Correct Answers for the Control and the Dyslexic Children

\begin{tabular}{lcc}
\hline & \multicolumn{2}{c}{ Performance of Correct Answers (\%) } \\
\cline { 2 - 3 } & Phoneme Substitution & Oddity Task \\
\hline $\begin{array}{l}\text { Control children } \\
(n=15)\end{array}$ & $98.5 \pm 2.3$ & $85.3 \pm 18.6$ \\
$\begin{array}{l}\text { Dyslexic children } \\
(n=15)\end{array}$ & $70.7 \pm 32.3$ & $65.3 \pm 28.2$ \\
\hline
\end{tabular}


between the two groups $(z=-1.92, p<.05)$, suggesting that dyslexic children performed worse in the rhyme detection task than the unimpaired control children. The results suggest that children with developmental dyslexia are deficient in the processing of segmental phonological information.

\section{Performance in the Grammaticality Judgment Task}

Control children as well as children with developmental dyslexia performed above chance level in the grammaticality judgment task. The results are presented in Table 4. The ANOVA yielded a main effect of condition, $F(2,29)=10.35, M S E=23.7, p<.01$, and a main effect of group, $F(1,30)=11.55, M S E=38.6, p<.01$, but no other significant differences. The main effect of group reflects that the control children had a better overall performance than the dyslexic participants. For the main effect of condition, a follow-up analysis in a pairwise comparison of the conditions independent of the group was conducted, and it revealed a significant difference between the semantic violation condition and the correct condition (correct condition: 91.9\%; semantic violation condition: $96.0 \%, p<.001)$. This implies that semantically incorrect sentences were more often correctly classified than sentences of the correct condition. This might be because of a higher expectedness of the sentence final element that is not fulfilled by the upcoming element.

The analysis of the reaction times revealed no main effect of condition $(F<1)$ or group $(F<1)$ and no significant interaction $(F<1)$. This is not a surprising result because the judgment was required $3000 \mathrm{msec}$ after the offset of the sentences, and it therefore does not represent on-line sentence comprehension.

\section{Event-related Brain Potential Data}

\section{Sentence Comprebension}

The ERPs of the control children and the dyslexic children evoked by the syntactic violation and the semantic violation are presented in Figures 2 and 3, respectively. The corresponding difference waves are shown in Figure 4. For each TW, an analysis with the between-subject variable group (dyslexic children vs. control children) and three within-subject variables (condition: correct vs. incorrect; hemisphere: left vs. right; region: anterior vs. posterior) was conducted. Whenever there was a significant two- or three-way interaction between the variable group and condition and one of the topographical variables, a subsequent analysis was performed for each group of children.

For the syntactic violation condition, a biphasic pattern with an early anterior negativity commonly referred to as ELAN followed by a P600 component was observed for the control children. The anterior negativity showed an early beginning, as reported for 13-year-old teenagers and adults (Hahne et al., 2004), and sustained until $600 \mathrm{msec}$ poststimulus onset. The anterior negativity for the control children was bilaterally distributed. The P600 had its onset at $600 \mathrm{msec}$ and remained until $1300 \mathrm{msec}$, which is also in agreement with earlier findings (Hahne et al., 2004). The results for the dyslexic children exhibited some similarities with respect to the $\mathrm{P} 600$ but also remarkable differences with respect to the anterior negativity observed for the control children. The anterior negativity for the dyslexic children was delayed starting about 300 msec. The P600 displayed a similar pattern for the dyslexic children as well as for the control children.

For TW 1 (100-300 msec) and TW 2 (300-600 msec), the analyses revealed a significant main effect of condition and a reliable three-way interaction of the variables group, condition, and region for the lateral electrodes, but no significant effect for the midline electrodes (see Table 5). For TW 3 (600-1300 msec), a significant main effect of condition was observed for the midline electrodes, but no other main effect or interaction was found for the lateral electrodes.

Following the three-way interaction between the variables group, condition, and region in TWs 1 and 2, analyses were calculated with the variables condition (correct vs. syntactically incorrect) and electrode for each region (anterior: FP1/2, F7/8, F3/4, and FT9/10; posterior: C3/4, $\mathrm{T} 5 / 6, \mathrm{P} 3 / 4$, and $\mathrm{O} 1 / 2$ ) and group (see Table 6). In TW 1 , for the control children, a reliable main effect of condition was observed in the anterior region, reflecting an early anterior negativity (see Table 6). There was also a significant two-way interaction between condition and electrode. Follow-up analyses on the electrode level revealed a reliable negativity for all anterior electrodes. The interaction between condition and electrode observed here is because of larger amplitudes of the

Table 4. Means $( \pm S D)$ of Performance of Correct Answers for the Control and the Dyslexic Children in the EEG Experiment

\begin{tabular}{lccc}
\hline & \multicolumn{3}{c}{ Performance of Correct Answers (\%) } \\
\cline { 2 - 4 } & Correct Sentences & Semantically Incorrect Sentences & Syntactically Incorrect Sentences \\
\hline Control children $(n=16)$ & $93.8 \pm 4.3$ & $97.6 \pm 2.8$ & $96.2 \pm 3.2$ \\
Dyslexic children $(n=16)$ & $89.8 \pm 5.4$ & $94.3 \pm 4.0$ & $90.6 \pm 8.9$ \\
\hline
\end{tabular}




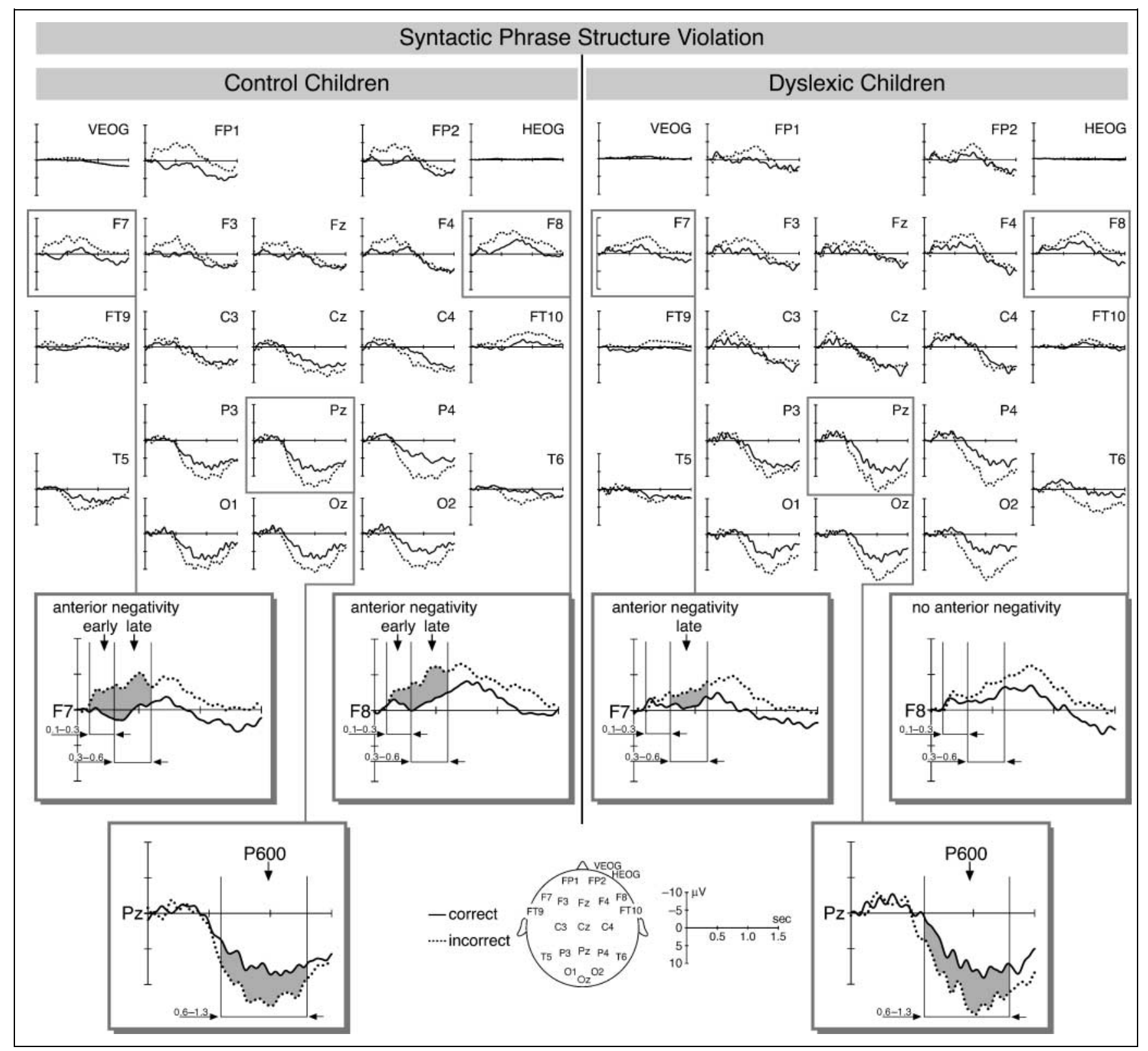

Figure 2. Grand average ERPs of the control (left) and dyslexic children (right) in the syntactic violation condition. The syntactically incorrect condition (dotted line) is plotted against the correct condition (solid line). The axis of the ordinates indicates the onset of the critical word (past participle). Negative voltage is plotted upward. The gray hatched sections refer to TWs that were statistically tested and revealed significance.

negativity at frontal electrodes and smaller amplitudes at the fronto-temporal electrodes for the violation condition. For the dyslexic children, no effect reached significance (see Table 6).

In TW 2, for the control children, a main effect of condition for the anterior region was found, supporting the presence of an anterior negativity. No such effect was observed for the posterior region. A reliable twoway interaction of condition and electrode was observed for the anterior region for the same group of children. In a subsequent follow-up analysis, a significant effect of condition was found at all electrodes. This negativity showed slight differences in amplitude across the differ- ent electrodes and is more pronounced over frontal electrodes compared with fronto-temporal electrodes. For the dyslexic children, a reliable effect of condition was observed for the anterior region. For the posterior region, a marginally significant interaction between condition and electrode was found. Further analyses on the electrode level revealed a reliable effect of condition only at the right occipital electrode (O2) and showed a marginally significant difference in the conditions at the right temporal electrode (T6).

In summary, for the syntactic violation condition, control children showed a reliable anterior negativity for TW 1 (100-300 msec) and TW 2 (300-600 msec). In con- 


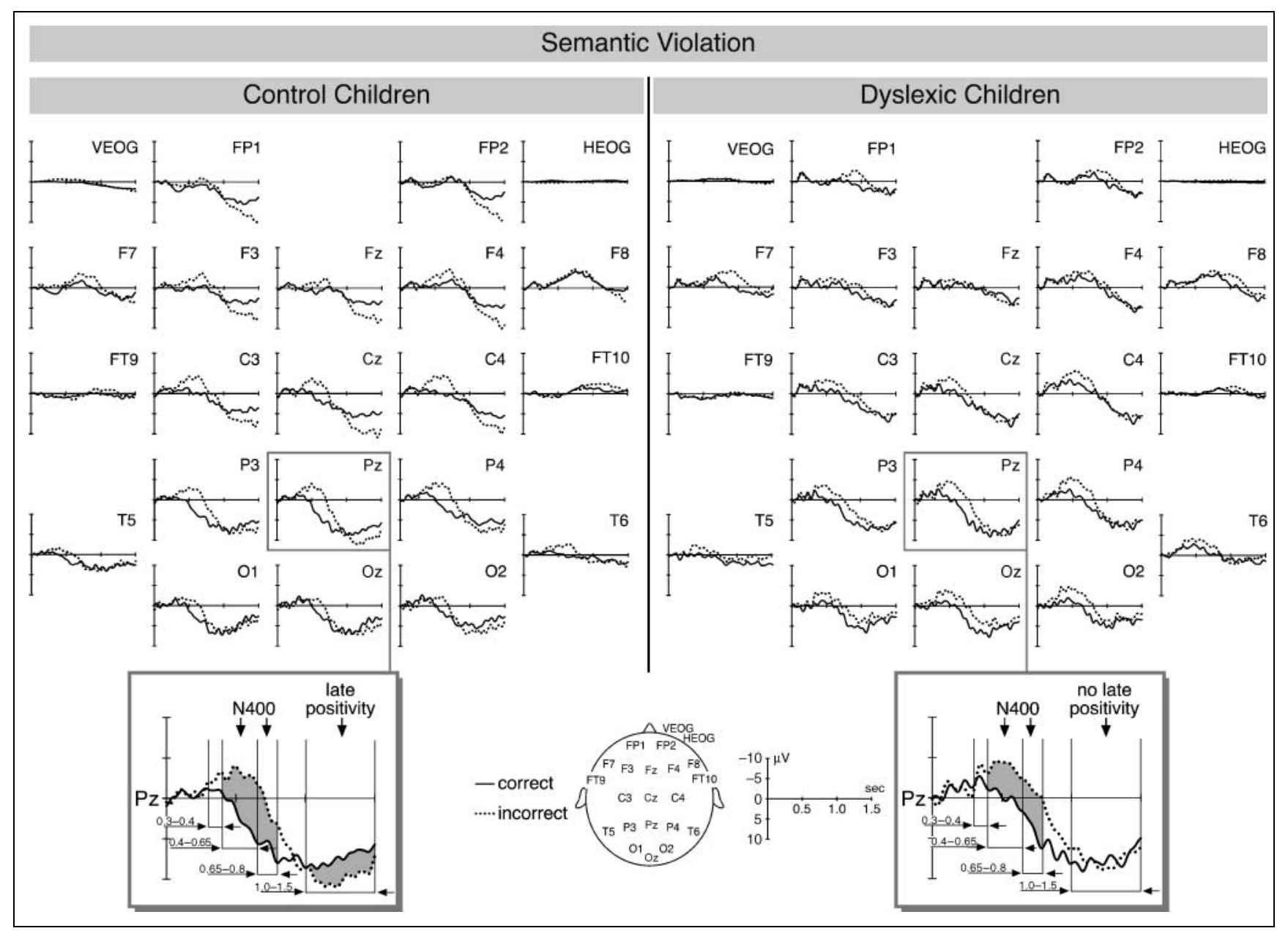

Figure 3. Grand average ERPs of the control children (left) and the dyslexic children (right) in the semantic violation condition. The semantically incorrect condition (dotted line) is plotted against the correct condition (solid line). The axis of the ordinates indicates the onset of the critical word (past participle). Negative voltage is plotted upward. The gray hatched sections refer to TWs that were statistically tested and revealed significance.

trast, the dyslexic children demonstrated a rather different pattern by showing an anterior negativity only for TW 2 (300-600 msec). A reliable late positivity for TW 3 (600-1300 msec) was observed for both the control and the dyslexic children.

ERP studies on the development of language comprehension using similar syntactic constructions showed that early syntactic processes, in particular, as reflected by the early anterior negativity, develop gradually (Hahne et al., 2004), such that an adultlike ELAN emerges only in 13-year-olds, whereas 10-year-olds show a left anterior negativity for the later TW. These results suggest that substantial developmental changes occur within an age range of 7-13 years. The participants of the present study fall within this age range, and we therefore sought to gain further insight into the differences observed for the anterior negativity in the early and the late TWs by conducting additional comparisons, analyzing the left and right anterior regions for each group and for each TW, separately. The following variables were included in the analyses conducted below: con- dition (correct vs. incorrect) and electrode (left anterior: FP1, F7, F3, and FT9; right anterior: FP2, F8, F4, and FT10).

The analyses of the left and the right anterior regions in TW 1 for the control children revealed a significant main effect of condition [left anterior: $F(1,15)=15.48$, $M S E=12.42, p<.01 ;$ right anterior: $F(1,15)=9.80$, $M S E=8.83, p<.01]$ and a reliable interaction between electrode and condition for the left side only [left anterior: $F(3,45)=4.72, M S E=1.28, p<.05$, right anterior: $F(3,45)=2.11, M S E=1.56, p=.15]$. As already described above, the interaction reflects amplitude differences due to a larger negativity at frontal electrodes compared with the fronto-temporal electrode. The results show a reliable early anterior negativity with a bilateral distribution. In contrast, no significant effect of condition, neither for the left nor the right anterior region, was observed for the dyslexic children (left and right anterior: $F<1$ ). For the control children, in TW 2 , a similar pattern was observed as for the early TW, yielding a negativity over left, $F(1,15)=28.80, M S E=$ 


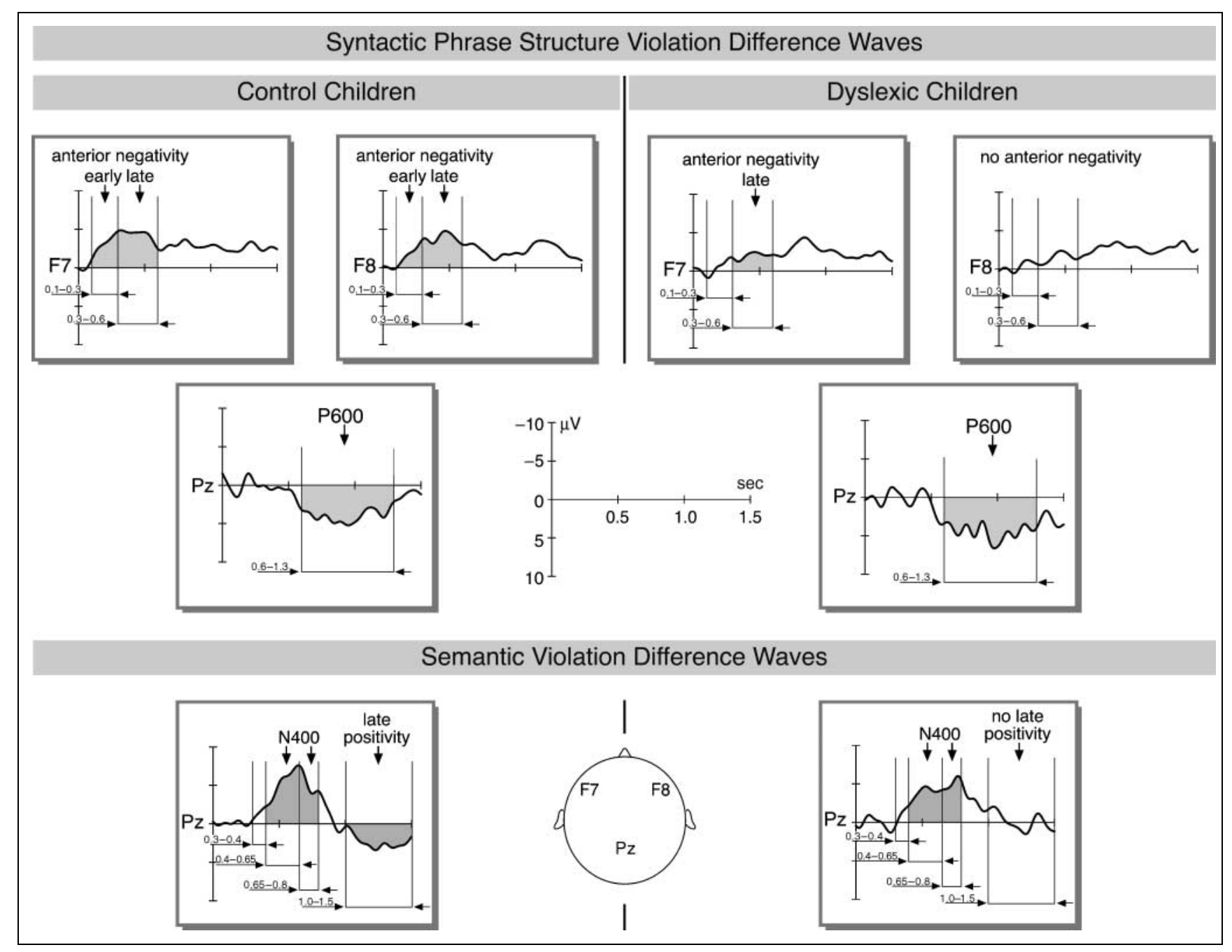

Figure 4. Difference waves for the control children (left) and the dyslexic children (right) in the syntactic violation condition (upper row) and the semantic violation condition (lower row). The difference waves were calculated by subtracting the grand average ERPs of the correct condition from the incorrect conditions. The axis of the ordinates indicates the onset of the critical word (past participle). Negative voltage is plotted upward. The gray hatched sections refer to TWs that were statistically tested and revealed significance.

$15.26, p<.001$, and right frontal electrodes, $F(1,15)=$ 27.07, MSE $=13.46, p<.001$, and additionally an interaction between condition and electrode for both regions [left: $F(3,45)=6.21, M S E=4.42, p<.01$, right: $F(3,45)=4.48, M S E=2.47, p<.05]$. Again, the interaction refers to amplitude differences, with a larger negativity at frontal electrodes than at the fronto-temporal electrode. A different pattern of results emerged for the dyslexic children, showing a main effect of condition only for the left anterior region, $F(1,15)=4.48, M S E=$ $23.10, p=.05$, but not for the right anterior region, $F(1,15)=2.79, M S E=21.32, p=.12$.

In summary, control children showed a bilaterally distributed early anterior negativity (100-300 msec) as well as a bilateral negativity between 300 and $600 \mathrm{msec}$. Dyslexic children demonstrated a slightly different ERP pattern, without any reliable effect for the early TW, and an anterior negativity (300-600 msec) restricted only to the left region.
For the semantic violation condition, descriptively, both the control children and the dyslexic children demonstrated an N400 effect. The N400 of both groups showed a similar centro-parietal distribution. The control children additionally showed a broadly distributed late positivity, which was not observed for the dyslexic children.

For TW 1 (300-400 msec), no significant main effects or interactions were observed (all $p>12$ ). For TW 2 (400-650 msec) and TW 3 (650-800 msec), for both the lateral and the midline electrodes, a significant main effect of condition was found. These results reflect a reliable N400 effect between 400 and $800 \mathrm{msec}$ poststimulus onset. Crucially, there was no main effect of group or any significant interaction (see Table 7) reflecting a comparable $\mathrm{N} 400$ for the control children and the dyslexic children. For TW 4 (1000-1500 msec), a significant main effect of condition and a Group $\times$ Condition interaction were found for the midline electrodes. For 
Table 5. Global Analyses of ERP Data for Children of the Control and the Dyslexic Group in the Syntactic Violation Condition Compared with the Correct Condition

\begin{tabular}{|c|c|c|c|c|c|c|c|c|c|c|c|}
\hline & \multirow[b]{3}{*}{ Source } & \multirow[b]{3}{*}{$d f$} & \multicolumn{9}{|c|}{ Syntactic Violation Condition vs. Correct Condition } \\
\hline & & & \multicolumn{3}{|c|}{$T W 1(100-300 \mathrm{msec})$} & \multicolumn{3}{|c|}{$T W 2(300-600 \mathrm{msec})$} & \multicolumn{3}{|c|}{ TW $3(600-1300 \mathrm{msec})$} \\
\hline & & & $F$ & $M S E$ & $p$ & $F$ & $M S E$ & $p$ & $F$ & MSE & $p$ \\
\hline \multirow{6}{*}{ 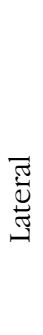 } & Group & 1,30 & $<1$ & & & $<1$ & & & $<1$ & & \\
\hline & Cond & 1,30 & 5.41 & 6.56 & $<.05$ & 6.15 & 10.48 & $<.05$ & $<1$ & & \\
\hline & Group $\times$ Cond & 1,30 & $<1$ & & & 1.39 & 14.61 & .25 & $<1$ & & \\
\hline & Group $\times$ Cond $\times$ Reg & 1,30 & 8.46 & 18.84 & $<.01$ & 5.83 & 16.12 & $<.05$ & $<1$ & & \\
\hline & Group $\times$ Cond $\times$ Hem & 1,30 & $<1$ & & & $<1$ & & & $<1$ & & \\
\hline & Group $\times$ Cond $\times$ Reg $\times$ Hem & 1,30 & 1.69 & .66 & .20 & 1.60 & 1.49 & .22 & 1.59 & 2.41 & .22 \\
\hline \multirow{4}{*}{$\stackrel{\stackrel{\Xi}{\Xi}}{\stackrel{\Xi}{\Xi}}$} & Group & 1,30 & $<1$ & & & 1.40 & 64.80 & .25 & $<1$ & & \\
\hline & Cond & 1,30 & 1.62 & 13.39 & .21 & $<1$ & & & 11.20 & 25.46 & $<.01$ \\
\hline & Group $\times$ Cond & 1,30 & $<1$ & & & $<1$ & & & $<1$ & & \\
\hline & Group $\times$ Cond $\times$ Elec & 3,90 & 1.74 & 4.63 & .19 & 1.77 & 7.47 & .18 & $<1$ & & \\
\hline
\end{tabular}

Significant effects are marked in boldface. Additional analyses were conducted for italicized results and reported in the text. Cond $=$ condition; Reg $=$ region; Hem $=$ hemisphere; Elec $=$ electrode .

the lateral electrodes, a marginally significant interaction of group and condition was observed (see Table 7). Subsequent analyses for each group, containing the variables condition (correct vs. semantically incorrect) and electrode (lateral electrodes: FP1/2, F7/8, F3/4, FT9/10, C3/4, T5/6, P3/4, and O1/2; midline electrodes: $\mathrm{Fz}, \mathrm{Cz}, \mathrm{Pz}$, and $\mathrm{Oz}$ ) were conducted (see Table 8). For the control children, there was a main effect of condi- tion for the midline electrodes, whereas a marginally significant effect of condition and an interaction between condition and electrode were observed for the lateral electrodes. Follow-up analyses for the control children on the electrode level revealed a reliable positivity for the lateral electrodes $\mathrm{F} 3, \mathrm{C} 3, \mathrm{C} 4$, and $\mathrm{P} 4$ (all $p \leq .05$ ) and a marginally significant positivity for FP1, FP2, F4, FT10, and $\mathrm{O} 2$ (all $p \leq .09$ ). In contrast, there was no

Table 6. Follow-up Analyses of ERP Data for Children of the Control Group and the Dyslexic Group Separately in the Syntactic Violation Condition Compared with the Correct Condition

\begin{tabular}{|c|c|c|c|c|c|c|c|c|c|}
\hline \multirow{3}{*}{$\begin{array}{l}\text { ज्ञ } \\
\text { डे }\end{array}$} & \multirow[b]{3}{*}{ Source } & & \multirow[b]{3}{*}{$d f$} & \multicolumn{6}{|c|}{ Syntactic Violation Condition vs. Correct Condition } \\
\hline & & & & \multicolumn{3}{|c|}{$T W 1(100-300 \mathrm{msec})$} & \multicolumn{3}{|c|}{ TW 2 (300-600 msec) } \\
\hline & & & & $F$ & $M S E$ & $p$ & $F$ & $M S E$ & $p$ \\
\hline \multirow{4}{*}{ 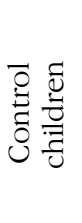 } & \multirow{2}{*}{ Anterior } & Cond & 1,15 & 14.22 & 18.87 & $<.01$ & 36.13 & 22.20 & $<.001$ \\
\hline & & Cond $\times$ Elec & 7,105 & 3.53 & 1.55 & $<.05$ & 4.32 & 3.89 & $<.001$ \\
\hline & \multirow{2}{*}{ Posterior } & Cond & 1,15 & $<1$ & & & $<1$ & & \\
\hline & & Cond $\times$ Elec & 7,105 & 1.22 & 1.83 & .31 & 1.67 & 4.61 & .17 \\
\hline \multirow{4}{*}{ 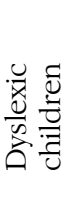 } & \multirow{2}{*}{ Anterior } & Cond & 1,15 & $<1$ & & & 4.74 & 33.74 & $<.05$ \\
\hline & & Cond $\times$ Elec & 7,105 & $<1$ & & & $<1$ & & \\
\hline & \multirow{2}{*}{ Posterior } & Cond & 1,15 & $<1$ & & & $<1$ & & \\
\hline & & Cond $\times$ Elec & 7,105 & 1.02 & 3.05 & .39 & 2.43 & 6.19 & .08 \\
\hline
\end{tabular}

Significant effects are marked in boldface. Additional analyses were conducted for italicized results and reported in the text. Cond $=$ condition; Elec $=$ electrode. 
Table 7. Global Analyses of ERP Data for Children of the Control Group and the Dyslexic Group in the Semantic Violation Condition Compared with the Correct Condition

\begin{tabular}{|c|c|c|c|c|c|c|c|c|c|c|c|c|c|c|c|}
\hline & \multirow{3}{*}{\multicolumn{2}{|c|}{ Source }} & \multirow[b]{3}{*}{$d f$} & \multicolumn{12}{|c|}{ Semantic Violation Condition vs. Correct Condition } \\
\hline & & & & \multicolumn{3}{|c|}{$\begin{array}{c}T W 1 \\
(300-400 \mathrm{msec})\end{array}$} & \multicolumn{3}{|c|}{$\begin{array}{c}T W 2 \\
(400-650 \mathrm{msec})\end{array}$} & \multicolumn{3}{|c|}{$\begin{array}{c}T W 3 \\
(650-800 \mathrm{msec})\end{array}$} & \multicolumn{3}{|c|}{$\begin{array}{c}T W 4 \\
(1000-1500 \mathrm{msec})\end{array}$} \\
\hline & & & & $F$ & $M S E$ & $p$ & $F$ & $M S E$ & $p$ & $F$ & $M S E$ & $p$ & $F$ & $M S E$ & $p$ \\
\hline \multirow{6}{*}{ 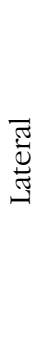 } & Group & & 1,30 & 1.53 & 25.93 & .23 & 1.04 & 39.05 & .32 & $<1$ & & & $<1$ & & \\
\hline & Cond & & 1,30 & 2.58 & 18.82 & .12 & 10.98 & 15.96 & $<.01$ & 17.59 & 11.52 & $<.001$ & $<1$ & & \\
\hline & Group $x$ & Cond & 1,30 & $<1$ & & & $<1$ & & & $<1$ & & & 3.21 & 18.53 & .08 \\
\hline & Group $x$ & Cond $\times$ Reg & 1,30 & 1.68 & 6.28 & .20 & $<1$ & & & $<1$ & & & $<1$ & & \\
\hline & Group $\times$ & Cond $\times$ Hem & 1,30 & $<1$ & & & $<1$ & & & $<1$ & & & $<1$ & & \\
\hline & Group $\times$ & Cond $\times$ Reg $\times$ Hem & 1,30 & $<1$ & & & $<1$ & & & $<1$ & & & $<1$ & & \\
\hline \multirow{4}{*}{$\stackrel{\mathscr{\Xi}}{\stackrel{\Xi}{\Xi}} \underset{\Xi}{\Sigma}$} & Group & & 1,30 & 1.24 & 42.34 & .27 & 1.57 & 53.51 & .22 & $<1$ & & & $<1$ & & \\
\hline & Cond & & 1,30 & 1.86 & 32.94 & .18 & 18.97 & 27.50 & $<.001$ & 24.17 & 21.90 & $<.001$ & 4.50 & 22.04 & .04 \\
\hline & Group $\times$ & Cond & 1,30 & $<1$ & & & $<1$ & & & $<1$ & & & 5.39 & 22.04 & .03 \\
\hline & Group $\times$ & Cond $\times$ Elec & 3,90 & 1.12 & 5.95 & .33 & $<1$ & & & $<1$ & & & $<1$ & & \\
\hline
\end{tabular}

Significant effects are marked in boldface. Additional analyses were conducted for italicized results and reported in the text. Cond $=$ condition; Reg $=$ region; Hem $=$ hemisphere; Elec $=$ electrode.

significant main effect of condition or a significant interaction between condition and electrode for the dyslexic children.

In summary, for the semantic violation condition, a comparable N400 (400-800 msec) was observed for the control and dyslexic children. For the control children, in addition to the $\mathrm{N} 400$, a late positivity $(1000-1500 \mathrm{msec})$ was found over lateral and midline electrodes, whereas such a positivity was absent for the dyslexic children.

\section{Early Auditory Processing}

The auditory potentials evoked by the sentence onset showed a similar P1-N1-P2 complex with respect to

Table 8. Follow-up Analyses of the ERP Data for Children of the Control Group and the Dyslexic Group Separately in the Semantic Violation Condition Compared with the Correct Condition

\begin{tabular}{|c|c|c|c|c|c|c|}
\hline \multirow{3}{*}{ है } & & & \multirow[b]{3}{*}{$d f$} & \multicolumn{3}{|c|}{ Semantic Violation Condition vs. Correct Condition } \\
\hline & & & & & $00-150$ & \\
\hline & \multicolumn{2}{|l|}{ Source } & & $F$ & $M S E$ & $p$ \\
\hline \multirow{4}{*}{ 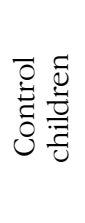 } & \multirow{2}{*}{ Lateral } & Cond & 1,15 & 3.10 & 61.87 & .10 \\
\hline & & Cond $\times$ Elec & 15,225 & 2.44 & 5.94 & .07 \\
\hline & \multirow{2}{*}{ Midline } & Cond & 1,15 & 12.76 & 17.06 & $<.01$ \\
\hline & & Cond $\times$ Elec & 3,45 & 1.25 & 7.61 & .30 \\
\hline \multirow{4}{*}{ 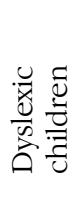 } & \multirow{2}{*}{ Lateral } & Cond & 1,15 & $<1$ & & \\
\hline & & Cond $\times$ Elec & 15,225 & $<1$ & & \\
\hline & \multirow{2}{*}{ Midline } & Cond & 1,15 & $<1$ & & \\
\hline & & Cond $\times$ Elec & 3,45 & 1.11 & 6.48 & .34 \\
\hline
\end{tabular}

Significant effects are marked in boldface. Additional analyses were conducted for italicized results and reported in the text. Cond $=$ condition; Elec $=$ electrode. 
latency for the control and dyslexic children. The peak latencies for the P1, N1, and P2 at the electrodes C3, C4, and $\mathrm{Cz}$ are reported in Table 9. Pairwise $t$ tests did not reveal any significant difference between the groups (all $p \geq .09$ ).

\section{DISCUSSION}

Utilizing ERP measures, the present study investigated auditory sentence comprehension in children with developmental dyslexia and control children. We posed the question whether children with developmental dyslexia differ in the syntactic processing and if so, whether this is because of differences in prosodic processes that have an impact on the processing of syntactic information. We further tested whether the differences between control children and children with developmental dyslexia are specific to the domains of prosody and syntax or hold also for the lexical-semantic domain. In addition, we examined both the level of phonological encoding (i.e., segmental phonological information) and the level of prosodic encoding (i.e., suprasegmental phonological information), as well as early auditory processing and its input on phonological processing. The comparison between the phonological processes and processes of early auditory perception should help to disentangle whether a phonological deficit or an auditory temporal deficit can be observed in children with developmental dyslexia. In the following, we first discuss the findings (behavioral results and the ERP results) from sentence comprehension. Second, we discuss the results for the processing of segmental and prosodic phonological information. Third, we discuss the findings for the early auditory processing.

\section{Sentence Comprehension}

\section{Behavioral Data}

In the grammaticality judgment task, children with developmental dyslexia and control children both performed well, the control children however showing a better performance, independently of the conditions. The fact that children with developmental dyslexia demonstrated poorer language comprehension abilities points toward a language comprehension deficit for at least some of these children. This conclusion is consistent with previous findings that focused on different aspects of language comprehension in children with developmental dyslexia (Gallagher, Frith, \& Snowling, 2000; McArthur, Hogben, Edwards, Heath, \& Mengler, 2000).

Both control children and children with developmental dyslexia detected the semantic violation more often than the syntactic violation. This suggests that the processing of semantic information is relatively intact. Moreover, correct sentences were less often recognized as correct than sentences with the semantic violation were identified as correct, which could be because of the fact that sentences with a violation are very rare in everyday conversation, therefore, catching children's attention more often than correct sentences. Being in the experimental setting, children might expect the presentation of sentences with a violation more often than the presentation of sentences without a violation.

\section{Syntactic Violation Condition}

For the syntactic violation condition, a combined pattern, comprising a bilaterally distributed early anterior negativity and a P600, was observed only for the control children. The children with developmental dyslexia showed a slightly different pattern containing a delayed anterior negativity restricted to the left hemisphere and a P600 component. In the following, these findings will be discussed in detail for each of the selected TW separately.

Converging with findings from Hahne et al. (2004), a bilaterally distributed early anterior negativity (100$300 \mathrm{msec}$ ) was observed for the control children. In contrast, for children with developmental dyslexia, no early anterior negativity was observed within this TW. The ELAN is assumed to reflect early processes of phrase structure building based on word category information, and Hahne and Friederici (1999) showed that these processes are highly automatic. Critically, the ELAN has also been reported for healthy children aged 2 years 8 months in simple active sentences (Oberecker et al., 2005). This suggests that in these healthy children, a neural processing system, as observed in adults, has been established for the processing of default structures in active sentences, but that it takes some years before it is applied in an adultlike manner to more complex syntactic structures, such as passive sentences (Hahne et al., 2004).

Table 9. Averages $( \pm S D)$ of Peak Latencies (Milliseconds) of the P1, N1, and P2 for Control and Dyslexic Children

\begin{tabular}{|c|c|c|c|c|c|c|}
\hline & \multicolumn{3}{|c|}{ Control Children $(n=16)$} & \multicolumn{3}{|c|}{ Dyslexic Children $(n=16)$} \\
\hline & C3 & C4 & $C z$ & C3 & C4 & $C z$ \\
\hline P1 & 70.7 (17.9) & $76.0(18.8)$ & $71.2(20.0)$ & $69.7(16.8)$ & $67.7(16.8)$ & $69.0(16.5)$ \\
\hline N1 & $116.7(16.1)$ & $121.0(9.7)$ & 114.7 (11.6) & $117.7(12.5)$ & $118.2(13.1)$ & $112.7(12.1)$ \\
\hline P2 & 203.7 (18.8) & $202.0(13.9)$ & $198.2(11.0)$ & 203.7 (21.2) & $206.0(15.9)$ & $206.7(16.6)$ \\
\hline
\end{tabular}


Functionally, a right fronto-temporal network has been associated with the processing of prosodic information (Friederici \& Alter, 2004). This idea of a right inferior frontal involvement in the detection of prosodic anomalies received further support by a recent ERP study (Eckstein \& Friederici, 2005), where a RAN was elicited for a prosodic incongruity, in which the sentence final word possessed the prosody of the penultimate word. The RAN was observed for sentences either containing a pure prosodic violation or a combined syntactic and prosodic violation, leading to the conclusion that the RAN reflects the processing of prosody (Eckstein \& Friederici, 2005). Furthermore, Eckstein and Friederici (in press) report that prosodic processes can influence early syntactic processes as evidenced by an involvement of the right anterior region.

The notion that processes reflecting syntactic phrase structure building are linked to left anterior regions and that prosodic processes are linked to right anterior regions is further supported by studies investigating phrase structure violations either using naturally produced sentences or sentences in which a constituent has been spliced out. A bilaterally distributed early anterior negativity has been reported for studies with auditorily presented sentences in which a constituent had been spliced out. Although a careful splicing procedure was applied, which controlled, for example, for local coarticulation, a prosodic incongruity was created as evidenced by the elicited ERP responses (Kubota, Ferrari, \& Roberts, 2004; Hahne \& Friederici, 1999, 2002; Knösche, Maess, \& Friederici, 1999). These results are in agreement with findings of the current study. Children of the control group showed also a bilaterally distributed early anterior negativity suggesting that both prosodic information and syntactic phrase structure information are processed.

In contrast, studies that presented naturally produced sentences without a prosodic incongruity reported an early anterior negativity that was more left-lateralized (Friederici, Gunter, Hahne, \& Mauth, 2004; Friederici, Hahne, \& Mecklinger, 1996, Experiment 1). Similarly, a more left-lateralized early negativity was observed for fast visually presented stimuli (Gunter, Friederici, \& Hahne, 1999; Friederici et al., 1996, Experiment 2). These findings suggest that there is less involvement of the right hemisphere when no prosodic incongruity is presented and when the sentences are not auditorily presented, so that prosodic information is indirectly available. Brain imaging experiments reported a right hemispheric activation for the processing of suprasegmental information (Gandour et al., 2004; Meyer, Alter, Friederici, Lohmann, \& von Cramon, 2002). These findings imply that the right anterior hemisphere supports the processing of prosodic information and that the left hemisphere supports the processing of syntactic information. Overall, the findings from the present study indicate that in the early TW, the control chil- dren activated left and right anterior regions during sentence comprehension, which we attribute to processes of phrase structure building and prosodic encoding respectively. Crucially, however, children with developmental dyslexia did not pattern with the control children and showed no effects over anterior electrode sites.

Within the later TW (300-600 msec), a bilaterally distributed late anterior negativity was found for the control children. In contrast, for the children with developmental dyslexia, a late anterior negativity that was restricted to the left anterior region was observed. The appearance of the late anterior negativity observed for the control group might suggest that enhanced processing resources are still required during the comprehension of the passive constructions (but see the work of Hahne et al., 2004). More crucial for the present research question is the observation that the left anterior negativity that is found within the later TW for the children with developmental dyslexia might reflect syntactic phrase structure building processes that are not developed to the same degree as generally expected for their age. This idea is based on findings from younger normally developing children (7-10 years old) who showed, similar to the children with developmental dyslexia, a left anterior negativity for the later TW but not for the early TW (Hahne et al., 2004). Consistent with this idea is that children with developmental dyslexia performed relatively well in detecting the syntactic violation, which means that they process syntactic phrase structure information, but not automatically and as early as control children of the same age. Finally, the absence of the right anterior negativity (RAN) in children with developmental dyslexia suggests that prosodic information might not be used in the same manner as by control children.

Turning to TW 3, as hypothesized, for both the control children and children with developmental dyslexia, a P600 component (600-1300 msec) was observed in addition to the anterior negativity. These P600 components had a similar distribution in the two groups and were mostly prominent over parietal and occipital regions. With respect to the phrase structure violation condition tested in this study, the P600 component generally reflects processes of syntactic reanalysis and repair that emerge during a late processing phase after the parser has detected a syntactic violation (Friederici, 2002). These processes are assumed to be highly controlled (Hahne \& Friederici, 1999). The presence of the P600 thus indicates that both children with developmental dyslexia and control children are sensitive to the syntactic violation. This is in line with recent developmental findings that showed that the P600 is present in normally developing 2-year-old children, when simple active sentences were used with a syntactic violation (Oberecker et al., 2005; Silva-Pereyra, Klarman, Lin, \& Kuhl, 2005). Furthermore, for the processing of complex passive structures, as presented in our study, a P600 has been reported in normally developing children from age 
7 years onward (Hahne et al., 2004). The emergence of the P600 further reveals that late controlled processes of revision were initiated and carried out in a similar manner in the two groups and therefore suggests that these processes are also present in children with developmental dyslexia.

\section{Semantic Violation Condition}

The ERP data for the semantic processing domain reveal that both children with developmental dyslexia and control children registered similar N400 components (between 400 and $800 \mathrm{msec}$ ) with comparable distributions. Our results indicate that the processing of semantic anomalies is carried out in a similar manner by both groups during auditory sentence comprehension. Comparable results, showing a similar N400 component for both the dyslexic and the control children, were obtained in an alliteration priming task that utilized words and nonwords (Bonte \& Blomert, 2004) and a categorization task using figures and words (Silva-Pereyra et al., 2003). The present results, however, differ from findings of a study conducted by Neville et al. (1993), which used a visual sentence comprehension paradigm and tested the semantic integration of the final word of the sentence into the preceding context in language-impaired children and unimpaired control children. In this study, the N400 of the language-impaired children had a larger amplitude compared with the $\mathrm{N} 400$ of the control children. The following is our explanation for the difference between the study of Neville et al. and the study presented in the current article. First, the children participating in the present study were on average 2 years older than the children involved in the study by Neville et al. Second, the present study was conducted using the auditory modality, testing semantic processes independent of reading, whereas Neville et al. utilized the visual modality. As Neville et al. pointed out, a considerable portion of the language-impaired children also develop signs of reading impairment, and as it turned out, "only 12 of the language-impaired subjects could read well enough to do the visual sentence task" (p. 250). Therefore, the increased amplitude of the $\mathrm{N} 400$ could be a consequence of the reading requirement, which is more demanding for the language-impaired children.

Interestingly, the semantic violation condition elicited in addition to the N400 a late, broadly distributed positivity between 1000 and $1500 \mathrm{msec}$ for the control children but not for the children with developmental dyslexia. The late positivity could be caused by the experimental setting and the task requirement. Performing a similar judgment task yielded an $\mathrm{N} 400$ followed by a P600 (650-850 msec) for adults (Kolk, Chwilla, van Herten, \& Oor, 2003). In the first experiment of this study among other conditions, sentences with a selectional restriction violation and acceptable sentences were compared. Participants had to judge the overall correctness of the sentences. To control the impact of the task, a second experiment was conducted in which participants had to read the sentences and to perform a probe verification task to ensure that they paid attention to the test sentences. In contrast to the first experiment, the P600 was absent, and only an N400 was observed. Kolk et al. (2003) interpreted the presence of the P600 in their first experiment as a consequence of the judgment task. However, the positivity observed in our study appeared later between 1000 and $1500 \mathrm{msec}$, which could be due to latency differences in the ERP components between children and adults. Similarly, a biphasic pattern containing an N400 and a late positivity was reported by Ors et al. (2001) and Holcomb et al. (1992). Again, in both studies, adults and children had to judge the congruency of a word with respect to its preceding context.

\section{Segmental and Suprasegmental Information}

As hypothesized, children with developmental dyslexia performed worse in the phoneme substitution task and also in the rhyme detection task. These findings are in agreement with the phonological deficit hypothesis (Goswami, 2003), which predicts an impairment in the processing of segmental phonological information. Furthermore, the absence of the RAN in the sentence comprehension task is here interpreted as an indication that children with developmental dyslexia do not rely on suprasegmental information in the way that normal children do. These findings reveal that the processing of both segmental and suprasegmental information differs in the children with developmental dyslexia and the control children. The present results therefore confirm the phonological deficit hypothesis and critically extend it to the assumption that the processing of suprasegmental information is also affected in children with developmental dyslexia.

\section{Early Auditory Processing}

For the auditory sentence onset potentials (P1-N1-P2 complex), similar peak latencies were found for both children with developmental dyslexia and control children. These results suggest that early auditory perception might not be impaired in our group of children with developmental dyslexia. These results are consistent with the findings of Neville et al. (1993). They found that the auditory ERP component (N140) was delayed in latency and reduced in its amplitude in the subgroup of language-impaired/reading-disabled children who scored poorly on the Tallal Auditory Repetition Test (Tallal, 1978), but not in the subgroup of languageimpaired/reading-disabled children that scored within the normal range on the same test. In their study, the 
same group of language-impaired/reading-disabled children was also divided into two groups, based on their performance on the Cycle Test of Syntax, to investigate whether there is any correlation in their impairment between auditory processing and the syntactic processing. Interestingly, they found that the languageimpaired/reading-disabled children who performed poorly on the auditory repetition task and exhibited a delayed and reduced N140 did not necessarily demonstrate impaired syntactic processes. Thus our findings, just as those of Neville et al. suggest that there is not obligatorily a functional link between the syntactic processing and the early auditory processing. Rather, the present results indicate an impairment in dyslexic children for the processing of suprasegmental auditory information.

\section{Conclusion}

The present study investigated ERPs to compare auditory sentence comprehension in 9- to 12-year-old children with developmental dyslexia and their controls, which were matched on age, sex, and nonverbal intelligence. Semantic processes as indicated by the N400 appeared to be very similar in both groups. Syntactic processes appeared to be different with respect to the early anterior negativity but similar with regard to the P600 component. The results for the P600 suggest comparable controlled processes of syntactic reanalysis. For the control children, automatic processes of syntactic structure building, as represented by the early left anterior negativity (ELAN), and the formation of prosodic structure, reflected in the RAN, were observed. In contrast, the dyslexic children showed a delayed anterior negativity (300-600 msec) compared with their agematched controls. It could be assumed that the left anterior negativity serves as a precursor for the ELAN, because dyslexic children were able to detect the syntactic violation in the behavioral task and performed on a high level. The absence of the RAN suggests that suprasegmental (prosodic) information, which provides an important cue in the acquisition of syntactic information, is not processed in the same manner as in unimpaired control children. Thus, the present findings strengthen the view that developmental dyslexia is associated with a phonological deficit that might hamper the acquisition of automatic syntactic processes.

\section{Acknowledgments}

We thank Masako Hirotani, Petra Burkhardt, and three anonymous reviewers, for their constructive comments on earlier versions of this article, and Monika Hage, Elisabeth Greiner, and Ulrike Barth, for their help with data collection. We also thank all children and their parents for participating in this study. This study was supported by the Deutsche Forschungsgemeinschaft (German Research Foundation, DFG) grant SU 135/3-1 awarded to W. v. S.
Reprint requests should be sent to Angela D. Friederici, Max Planck Institute for Human Cognitive and Brain Sciences, P.O. Box 500 355, 04303 Leipzig, Germany, or via e-mail: angelafr@ cbs.mpg.de.

\section{Notes}

1. Note that the present study was done in a clinical setting. Therefore, the two lateral electrodes (T3 and T4) were used to check for signs of epileptic seizure, and the EEG recorded by those electrodes were not included in the ERP analyses.

2. Note that one pair of children (i.e., one dyslexic child and his matched control) was excluded from the analyses of the phonological awareness task due to a technical error.

\section{REFERENCES}

Achenbach, T. M. (1998). CBCL/4-18 Elternfragebogen über das Verbalten von Kindern und Jugendlichen [Child Behavior Checklist (CBCL/4-18)]. Cologne: Arbeitsgruppe Kinder-, Jugend- und Familiendiagnostik (KJFD). (Original work published 1991).

Berwanger, D. (2002). Untersuchung der zeitlichen Diskriminationsfäbigkeit bei Kindern mit einer Sprachentwicklungsstörung und-oder LeseRechtschreibstörung. Munich: Verlag Dr. Hut.

Birkel, P. (1994a). Weingartener Grundwortschatz Rechtschreib-Test für dritte und vierte Klassen $(W R T 3+)$ [Weingarten basic vocabulary orthography test for 3rd- and 4th-graders]. Göttingen: Hogrefe.

Birkel, P. (1994b). Weingartener Grundwortschatz Rechtschreib-Test für zweite und dritte Klassen (WRT 2+) [Weingarten orthography test for 2nd- and 3rd-graders] Göttingen: Hogrefe.

Bonte, M. L., \& Blomert, L. (2004). Developmental dyslexia: ERP correlates of anomalous phonological processing during spoken word recognition. Brain Research, Cognitive Brain Research, 21, 360-376.

Bradley, L., \& Bryant, P. (1985). Rhyme and reason in reading and spelling. Ann Arbor, MI: University of Michigan Press.

Byrne, J. M., Connolly, J. F., MacLean, S., Dooley, J. M., Gordon, K. E., \& Beattie, T. L. (1999). Brain activity and language assessment using event-related potentials: Development of a clinical protocol. Developmental Medicine and Child Neurology, 41, 740-747.

Davis, C. J., Gayan, J., Knopik, V. S., Smith, S. D., Cardon, L. R., Pennington, B. F., Olson, R. K., \& DeFries, J. C. (2001). Etiology of reading difficulties and rapid naming: The Colorado twin study of reading disability. Behavior Genetics, 31, 625-635.

Dilling, H., Mombour, W., \& Schmidt, M. H. (1993). International classification of mental diseases, ICD-10 (German edition). Bern: Huber.

Eckstein, K., \& Friederici, A. (2005). Late interaction of syntactic and prosodic processes in sentence comprehension as revealed by ERPs. Brain Research, Cognitive Brain Research, 25, 130-143.

Eckstein, K., \& Friederici, A. D. (2006). It's early: ERP evidence for initial interaction of syntax and prosody in speech comprehension. Journal of Cognitive Neuroscience, 18, 1696-1711.

Esser, G., Wyschkon, A., \& Schmidt, M. H. (2002). Long-term outcome in 8-year-old children with specific reading retardation: Results at age 25 years. Zeitschrift für Klinische Psychologie und Psychotherapie, 31, 235-242. 
Fisher, S. E., \& DeFries, J. C. (2002). Developmental dyslexia: Genetic dissection of a complex cognitive trait. Nature Reviews Neuroscience, 3, 767-780.

Fisher, S. E., Francks, C., Marlow, A. J., MacPhie, I. L., Newbury, D. F., Cardon, L. R., Ishikawa-Brush, Y., Richardson, A. J., Talcott, J. B., Gayan, J., Olson, R. K., Pennington, B. F., Smith, S. D., DeFries, J. C., Stein, J. F., \& Monaco, A. P. (2002). Independent genome-wide scans identify a chromosome 18 quantitative-trait locus influencing dyslexia. Nature Genetics, 30, 86-91.

Friederici, A. D. (2002). Towards a neural basis of auditory sentence processing. Trends in Cognitive Sciences, 6, 78-84.

Friederici, A. D., \& Alter, K. (2004). Lateralization of auditory language functions: A dynamic dual pathway model. Brain and Language, 89, 267-276.

Friederici, A. D., Gunter, T. C., Hahne, A., \& Mauth, K. (2004). The relative timing of syntactic and semantic processes in sentence comprehension. NeuroReport, 15, 165-169.

Friederici, A. D., Hahne, A., \& Mecklinger, A. (1996). Temporal structure of syntactic parsing: Early and late event-related brain potential effects. Journal of Experimental Psychology: Learning, Memory, and Cognition, 22, 1219-1248.

Gallagher, A., Frith, U., \& Snowling, M. J. (2000). Precursors of literacy delay among children at genetic risk of dyslexia. Journal of Child Psychology and Psychiatry, and Allied Disciplines, 41, 203-213.

Gandour, J., Tong, Y., Wong, D., Talavage, T., Dzemidzic, M., $\mathrm{Xu}, \mathrm{Y}$., Li, X., \& Lowe, M. (2004). Hemispheric roles in the perception of speech prosody. Neuroimage, 23, 344-357.

Georgiewa, P., Grünling, C., Ligges, M., Filz, C., Moller, U., \& Blanz, B. (2004). Age dependent changes in phonological reading in dyslexia. Zeitschrift für Klinische Psychologie und Psychotherapie, 33, 281-289.

Goswami, U. (2003). Phonology, learning to read and dyslexia: A cross-linguistic analysis. In V. Csepe (Ed.), Dyslexia: Different brain, different behavior (Vol. 23, pp. 1-40). New York: Kluwer Academic Publishers.

Grund, M., Haug, G., \& Naumann, C. L. (1995). DRT 5 Diagnostischer Rechtschreibtest für 5. Klassen [Diagnostic orthography test for 5th-graders]. Weinheim: Beltz.

Grund, M., Haug, G., \& Naumann, C. L. (1998). DRT 4 Diagnostischer Rechtschreibtest für 4. Klassen [Diagnostic orthography test for 4th graders]. Göttingen: Beltz.

Gunter, T. C., Friederici, A. D., \& Hahne, A. (1999). Brain responses during sentence reading: Visual input affects central processes. NeuroReport, 10, 3175-3178.

Habib, M. (2000). The neurological basis of developmental dyslexia: An overview and working hypothesis. Brain, 123, 2373-2399.

Hagoort, P., Brown, C. M., \& Osterhout, L. (1999). The neurocognition of syntactic processing. In C. M. Brown \& P. Hagoort (Eds.), The neurocognition of language (pp. 273-316). New York: Oxford University Press.

Hahne, A., Eckstein, K., \& Friederici, A. D. (2004). Brain signatures of syntactic and semantic processes during children's language development. Journal of Cognitive Neuroscience, 16, 1302-1318.

Hahne, A., \& Friederici, A. D. (1999). Electrophysiological evidence for two steps in syntactic analysis: Early automatic and late controlled processes. Journal of Cognitive Neuroscience, 11, 194-205.

Hahne, A., \& Friederici, A. D. (2002). Differential task effects on semantic and syntactic processes as revealed by ERPs. Brain Research, Cognitive Brain Research, 13, 339-356.
Hirsh-Pasek, K., Kemler Nelson, D. G., Jusczyk, P. W., Cassidy, K. W., Druss, B., \& Kennedy, L. (1987). Clauses are perceptual units for young infants. Cognition, 26, 269-286.

Höhle, B., \& Weissenborn, J. (2003). German-learning infants' ability to detect unstressed closed-class elements in continuous speech. Developmental Science, 6, 122-127.

Holcomb, P. J., Coffey, S. A., \& Neville, H. J. (1992). Visual and auditory sentence processing: A developmental analysis using event-related brain potentials. Developmental Neuropsychology, 8, 203-241.

Holcomb, P. J., \& Neville, H. J. (1991). Natural speech processing: An analysis using event-related brain potentials. Psychobiology, 19, 286-300.

Jasper, H. H. (1958). The ten-twenty electrode system of the International Federation. Journal of Electroencephalography and Clinical Neurophysiology, 10, 371-375.

Jiménez, J. E., García, E., Estévez, A., Díaz, A., Ortiz, R., Rodrigo, M., Guzmán, R., Hernández-Valle, I., \& Hernández, S. (2004). An evaluation of syntactic-semantic processing in developmental dyslexia. Electronic Journal of Research in Educational Psychology, 2, 127-142.

Jusczyk, P. W. (2002). How infants adapt speech-processing capacities to native language structure. Current Directions in Psychological Science, 11, 15-18.

Kaufman, A. S., \& Kaufman, N. L. (1991). K-ABC KaufmanAssessment Battery for Children [Kaufman Assessment Battery for Children (K-ABC)] (P. Melchers \& U. Preuss, German version). Amsterdam: Swets \& Zeitlinger. (Original work published 1983).

Knösche, T. R., Maess, B., \& Friederici, A. D. (1999). Processing of syntactic information monitored by brain surface current density mapping based on MEG. Brain Topography, 12, 75-87.

Kolk, H. H. J., Chwilla, D. J., van Herten, M., \& Oor, P. J. W. (2003). Structure and limited capacity in verbal working memory: A study with event-related potentials. Brain and Language, 85, 1-36.

Kubota, M., Ferrari, P., \& Roberts, T. P. L. (2004). Human neuronal encoding of English syntactic violations as revealed by both $\mathrm{L} 1$ and $\mathrm{L} 2$ speakers. Neuroscience Letters, 368, 235-240.

Kutas, M., \& Federmeier, K. D. (2000). Electrophysiology reveals semantic memory use in language comprehension. Trends in Cognitive Sciences, 4, 463-470.

Landerl, K., Linortner, R., \& Wimmer, H. (1992). Phonological awareness and spelling acquisition in German language. Zeitschrift für Pädagogische Psychologie, 6, 17-33.

Landerl, K., Wimmer, H., \& Frith, U. (1997). The impact of orthographic consistency on dyslexia: A German-English comparison. Cognition, 63, 315-334.

Linder, M., \& Grissemann, H. (1980). Zürcher Lesetest (ZLT) [Zürcher reading test]. Bern: Huber.

McArthur, G. M., Hogben, J. H., Edwards, V. T., Heath, S. M., \& Mengler, E. D. (2000). On the "specifics" of specific reading disability and specific language impairment. Journal of Child Psychology and Psychiatry, and Allied Disciplines, 41, 869-874.

Meyer, M., Alter, K., Friederici, A. D., Lohmann, G., \& von Cramon, D. Y. (2002). FMRI reveals brain regions mediating slow prosodic modulations in spoken sentences. Human Brain Mapping, 17, 73-88.

Müller, R. (1997). DRT 3 Diagnostischer Rechtschreibtest 3 [Diagnostic orthography test for 3rd graders]. Göttingen: Beltz.

Muter, V., \& Snowling, M. (1997). Grammar and phonology predict spelling in middle childhood. Reading \& Writing, 9, 407-425. 
Nation, K., \& Snowling, M. J. (2000). Factors influencing syntactic awareness skills in normal readers and poor comprehenders. Applied Psycholinguistics, 21, 229-241.

Neville, H. J., Coffey, S. A., Holcomb, P. J., \& Tallal, P. (1993). The neurobiology of sensory and language processing in language-impaired children. Journal of Cognitive Neuroscience, 5, 235-253.

Oberecker, R., Friedrich, M., \& Friederici, A. D. (2005). Neural correlates of syntactic processing in two-year-olds. Journal of Cognitive Neuroscience, 17, 1667-1678.

Ors, M., Lindgren, M., Berglund, C., Hagglund, K., Rosen, I., \& Blennow, G. (2001). The N400 component in parents of children with specific language impairment. Brain and Language, 77, 60-71.

Pennington, B. F., Van Orden, G. C., Smith, S. D., Green, P. A., \& Haith, M. M. (1990). Phonological processing skills and deficits in adult dyslexics. Child Development, 61, 1753-1778.

Ponton, C., Eggermont, J. J., Khosla, D., Kwong, B., \& Don, M. (2002). Maturation of human central auditory system activity: Separating auditory evoked potentials by dipole source modeling. Clinical Neurophysiology, 113, 407-420.

Ramus, F. (2001). Outstanding questions about phonological processing in dyslexia. Dyslexia: The Journal of the British Dyslexia Association, 7, 197-216.

Ramus, F., Rosen, S., Dakin, S. C., Day, B. L., Castellote, J. M., White, S., \& Frith, U. (2003). Theories of developmental dyslexia: Insights from a multiple case study of dyslexic adults. Brain, 126, 841-865.

Rathenow, P. (1979). WRT 4/5 Westermann Rechtschreibtest 4/5 [Westermann orthography test 4/5]. Braunschweig: Westermann.

Rathenow, P., Vöge, J., \& Laupenmühlen, D. (1980). WRT $6+$ Westermann Rechtschreibtest $6+$ [Westermann Orthography Test $6+]$. Braunschweig: Westermann.

Rego, L. L. B., \& Bryant, P. E. (1993). The connection between phonological, syntactic and semantic skills and children's reading and spelling. European Journal of Psychology of Education, 8, 235-246.

Shaywitz, S. E., Shaywitz, B. A., Fletcher, J. M., \& Escobar, M. D. (1990). Prevalence of reading disability in boys and girls. Results of the Connecticut Longitudinal Study. Journal of the American Medical Association, 264, 998-1002.

Silva-Pereyra, J., Rivera-Gaxiola, M., Fernandez, T., Diaz-Comas, L., Harmony, T., Fernandez-Bouzas, A., Rodriguez, M., Bernal, J., \& Marosi, E. (2003). Are poor readers semantically challenged? An event-related brain potential assessment. International Journal of Psychophysiology, 49, 187-199.

Silva-Pereyra, J. F., Klarman, L., Lin, L. J. F., \& Kuhl, P. K. (2005). Sentence processing in 30-month-old children:
An event-related potential study. NeuroReport, 16, 645-648.

Snow, D., \& Balog, H. L. (2002). Do children produce the melody before the words? A review of developmental intonation research. Lingua, 112, 1025-1058.

Snowling, M., Nation, K., Moxham, P., Gallagher, A., \& Frith, U. (1997). Phonological processing skills of dyslexic students in higher education: A preliminary report. Journal of Research in Reading, 20, 31-41.

Steinhauer, K., Alter, K., \& Friederici, A. D. (1999). Brain potentials indicate immediate use of prosodic cues in natural speech processing. Nature Neuroscience, 2, 191-196.

Tallal, P. (1978). An experimental investigation of the role of auditory temporal processing in normal and disordered language development. In A. Caramazza \& E. Zurif (Eds.), Language acquisition and language breakdown: Parallels and divergences (pp. 25-61). Baltimore, MD: The John Hopkins University Press.

Tallal, P. (1980). Auditory temporal perception, phonics, and reading disabilities in children. Brain and Language, 9, 182-198.

Tallal, P., Miller, S., \& Fitch, R. H. (1993). Neurobiological basis of speech: A case for the preeminence of temporal processing. Annals of the New York Academy of Sciences, 682, 27-47.

Tallal, P., \& Piercy, M. (1973). Developmental aphasia: Impaired rate of non-verbal processing as a function of sensory modality. Neuropsychologia, 11, 389-398.

Tallal, P., \& Piercy, M. (1974). Developmental aphasia: Rate of auditory processing and selective impairment of consonant perception. Neuropsychologia, 12, 83-93.

Tallal, P., \& Stark, R. E. (1982). Perceptual/motor profiles of reading impaired children with or without concomitant oral language deficits. Annals of Dyslexia, 32, 163-176.

von Suchodoletz, W. (1999). 100 years of research on specific reading and spelling disorder-What is our knowledge today? Zeitschrift für Kinder- und Jugendpsychiatrie, 27, 199-206.

Wechsler, D. (2000). HAWIK-III Hamburg-WechslerIntelligenztest für Kinder [Wechsler Intelligence Scale for Children (WISC-III)] (U. Tewes, P. Rossmann, \& U. Schallberger, German version). Bern: Huber. (Original work published 1991).

Weinert, S. (1992). Deficits in acquiring language structure: The importance of using prosodic cues. Applied Cognitive Psychology, 6, 545-571.

Wimmer, H. (1993). Characteristics of developmental dyslexia in a regular writing system. Applied Psycholinguistics, 14, 1-33.

Witruk, E., Friederici, A. D., \& Lachmann, T. (2002). Basic functions of language, reading and reading disability. Dordrecht: Kluwer Academic Publishers. 